\title{
An Outbreak of Nutritional (Iron Deficiency) Anaemia in Weanling Stock Rats
}

\author{
By A. L. BACHARACH, W. F. J. CUTHBERTSON AND \\ DOREEN M. THORN'TON \\ Research Division, Glaxo Laboratories Ltd, Greenford, Middlesex
}

(Received I 3 October 1948)

Thousands of papers have been published to show the effect of dietary changes on laboratory animals. In these papers lies the foundation for much of our current knowledge about essential nutrients. Almost all of the diets used have been described as synthetic, semi-synthetic or made of purified constituents, or even, perhaps somewhat arrogantly, as 'of known composition'. Only a few of these papers, notably some classical reports by $\mathrm{H}$. C. Sherman and his colleagues at Columbia University, discuss the effect of stock diets on the health and performance of a laboratory rat-colony. Yet the nutrition of these animals stands, however obscurely, behind their performance when they are subsequently submitted to the exigencies of dietary investigations, pharmacological assays or laboratory experiments. We have therefore thought it to be a matter of possible interest to others engaged in raising a stock of normal healthy animals to put on record a recent experience of our own, as unexpected as it was illuminating, at any rate to us.

\section{Stock diet and modifications}

\section{EXPERIMENTAL}

The dietary level at which we have always aimed for our breeding colony has been one that supplied optimally all essential nutrients, including those, such as the fatsoluble vitamins, that may be stored in the maternal organism and transmitted to the young. These young, however, may be unsuitable, because they have been too well fed, for certain types of investigation. This is so in experiments requiring rapid depletion of vitamin $\mathrm{A}$, as in the ordinary assay technique involving cessation of weight increase with development of xerophthalmia and subsequent reversal by supplementary feeding of pro-vitamin or vitamin A. Following a suggestion made originally by Nelson (I928) it has consequently been the practice for many years in our laboratories to prepare animals for vitamin $A$ testing by putting mother and litter on a vitamin A-free diet during the latter part of lactation, generally from the roth day after the birth of the litter. The vitamin A-free diet contains a salt mixture of the usual type. At weaning, therefore, the young animals for vitamin $A$ test have been receiving for some I4 days this diet in place of our stock-colony diet (Bacharach, I933). For convenience, the compositions of both diets are given in Table $\mathrm{r}$. 
Table I. Constitutions of stock and vitamin A-free diets

$\begin{array}{lclr}\text { Stock diet, RBSS8 } & \text { Parts } & \text { Vitamin A-free diet } & \text { Parts } \\ \text { Flour } & 45^{\circ} & \text { Rice starch } & 450 \\ \text { Full-cream dried milk } & 200 & \text { Vitamin-free casein* } & 200 \\ \text { Dried yeast } & 25 & \text { Arachis oil } & 100 \\ \text { Yeast extract } & 25 & \text { Dried yeast } & 100 \\ & \text { Yeast extract } \dagger & 25 \\ & \text { Wheat germ (fat-free) } & 25 \\ & \text { Salt mixture LD } 6 \ddagger & 50 \\ \text { * Commercial high-grade lactic acid casein, extracted with hot ethanol. } \\ \text { † Commercial concentrated aqueous extract of whole yeast. } \\ \text { † See de Loureiro (r93I). }\end{array}$

\section{Nutritional anaemia suspected and confirmed}

In July 1947 it was observed by Mr G. W. Flynn, now Senior Technician responsible for rat and mouse breeding in our laboratories, that the albino 'A-free' young appeared healthier than the ordinary albino weanlings from mothers receiving only stock diet. He noticed especially that these weanlings had 'very pale eyes', that they weighed only about two-thirds of what we were accustomed to expect, that their ears, paws and tails were pale and that they felt cold to the touch.

It so happened that in May of that year, owing to changes in the Ministry of Food's regulations governing the use for animal feeding of food fit for human consumption, we had been forced to replace the $85 \%$ extraction flour in our stock breeding diet by Canadian ' $D$ ' flour, which contains only $70-72 \%$ of the whole wheat grain. This was, in point of fact, the second change made in the diet, for it had originally contained wholemeal ( $95-99 \%$ extraction) flour. When this ceased to be available owing to the war, it was replaced by National flour, at whatever was the current rate of extraction enforced. To make good any dietary consequent deficiencies, dried yeast was from that time onward included in the ration and minor adjustments were made in the amounts of the other three ingredients, to give a diet, RBSS 8 , of the constitution shown in Table I. Following the change in 1947, we were in fact using flour from waterdamaged sacks, but its condition was entirely satisfactory for the feeding of rats and mice when only the inner contents of the sacks were used. Further, there had been some transient difficulties in securing for our breeding stock the small supplements of fresh liver normally supplied, though this naturally did not affect the mothers and litters being 'run out' on the vitamin A-free diet, which never received any known or suspected source of carotene or vitamin A.

All the circumstances pointed to a nutritional anaemia of the hypochromic type associated with inadequate iron intake. We looked for this and we found it, but only in the animals (the WAG 'London' strain of Wistar rats) receiving stock diet, and not in those receiving the vitamin A-free diet from about ro days of age.

Chemical analysis confirmed the iron contents of the two diets calculated from knowledge of their constituents; iron citrate is the source in the vitamin A-free diet. Figures are given later.

The red blood-cell (R.B.C.) counts of young animals weaned on the vitamin A-free diet ranged from 3.5 to $4.0 \times 10^{6} / \mathrm{cu} . \mathrm{mm}$., values reported to be normal for healthy 
animals (Griffith \& Farris, 1942). Corresponding animals on stock diet, however, gave erythrocyte counts of $1 \cdot 5-2.8 \times 10^{6} / \mathrm{cu} . \mathrm{mm}$., though the cells were normal in size. So anaemic were these animals, however, that the collection of samples for haemoglobin estimation proved impracticable.

\section{Iron supplementation of stock diet}

As a result of these observations it was decided to carry out an experiment with an iron-supplemented variant of the current stock diet. The objects were to establish (I) that the histological anaemia of the weanlings could be prevented by addition of an inorganic iron salt to the stock diet RBSS 8; (2) that this simple modification of the diet would render it as suitable for maintenance of the stock colony as the original stock diets containing flour of 95 or $85 \%$ extraction; (3) normal values for the R.B.C.

\section{Table 2. Percentage constitutions of stock diets}

\begin{tabular}{lcc}
\multicolumn{1}{c}{ Ingredient } & RBSS 8 & RBSS 9 \\
Wheat flour & 64.2 & 57.9 \\
Full-cream dried milk & 28.6 & 33.0 \\
Dried yeast & 3.6 & 3.5 \\
Yeast extract & 3.6 & 3.5 \\
Bone meal & - & $2 \cdot 0$ \\
Ferrous sulphate & - & 0.1 \\
\cline { 2 - 3 } & I00.0 & $100 \cdot 0$
\end{tabular}

Supplement ICP used as $10 \%$ of diet RBSS 9

Ferrous sulphate, exsiccated (\%)

Bone meal (\%)

Wheat flour (\%)

counts of adolescent albino rats. It was realized that minor or subtle departures from optimum composition of a stock diet might only reveal themselves over a period of years; nevertheless, we were satisfied that restoration of the diet to the desired level might be legitimately assumed if a relatively small change in composition completely abolished the specific deficiency so unexpectedly encountered.

We therefore added ferrous sulphate to the stock diet in a quantity sufficient to increase its iron content several fold, and we also raised the calcium content by the addition of bone meal. As we included extra iron in the diet to compensate for reduced iron intake from low extraction flour, so we also increased the calcium content to buffer against reduced calcium and iron absorption that might follow any later enforced changes causing lower calcium utilization, such as reduction in proportion of milk solids or increase in phytic acid. A small addition was simultaneously made in the content of dried milk, not so much with a view to improving the diet's nutritional value as to give round figures for weighing out ingredients. By using a concentrate of white flour supplemented with bone meal and ferrous sulphate (exsiccated)-having the const:tution shown for supplement ICP above-we arrived at diet RBSS 9, the make-up of which is compared with that of RBSS 8 in Table 2.

For comparison we also give below the iron contents, as determined analytically, for 
the three diets. The amount of iron supplied by $0.1 \%$ of exsiccated ferrous sulphate in the diet RBSS 9 should be 230 p.p.m.:

\begin{tabular}{|c|c|c|}
\hline \multirow[b]{2}{*}{ Diet } & \multicolumn{2}{|c|}{ Iron (p.p.m.) } \\
\hline & Individual values & Mean \\
\hline $\begin{array}{l}\text { Vitamin A-free (RFY } 2 \text { EO) } \\
\text { Old stock (RBSS 8) } \\
\text { New stock (RBSS 9) }\end{array}$ & $\begin{array}{c}32,32 \\
10,14,16 \cdot 5,25 \\
(95)^{*} 200,250,200,220,200\end{array}$ & $\begin{array}{l}32 \\
16 \cdot 4 \\
220\end{array}$ \\
\hline
\end{tabular}

\section{Effects on erythrocyte counts}

We next compared directly the two stock diets for their ability to promote haemoglobin formation. Sixteen newly weaned rats from our stock breeding colony, eight males and eight females, were picked at random. All were born of pure-line albino (WAG) parents reared on stock diet RBSS 8; at the beginning of the experiment they showed the by then expected low erythrocyte counts. The rats were arbitrarily divided into two similar groups, of which one continued to receive diet RBSS 8 , while the other was given the enriched RBSS 9. One male and one female from each group were examined three times at fortnightly intervals, the animals being chosen in rotation in such a way that two sets of four animals were submitted to R.B.C. counts each week. This procedure was adopted in an attempt to avoid producing an artifact anaemia due to too frequent bleeding and to prevent too many counts having to be made on any one day. The findings on the sixteen animals are given in Table 3 .

'Table 3. Erythrocyte counts in weanling albino rats

\begin{tabular}{|c|c|c|c|c|c|c|}
\hline \multirow{3}{*}{$\begin{array}{c}\text { Days } \\
\text { since } \\
\text { weaning }\end{array}$} & \multicolumn{5}{|c|}{ Red blood cells $\left(\times 10^{6} /\right.$ cu.mm. blood $)$} & \\
\hline & \multicolumn{3}{|c|}{ Diet RBSS 8} & \multicolumn{3}{|c|}{ Diet RBSS 9} \\
\hline & $\hat{\sigma}$ & $q$ & Mean & $\hat{o}$ & ? & Mean \\
\hline & $\mathbf{I}$ & $\mathbf{2}$ & & 3 & 4 & \\
\hline$\circ$ & $3.4 I$ & $2 \cdot 68$ & 3.05 & $\mathbf{r} \cdot 94$ & $4 \cdot \pi 9$ & $3 \cdot 12$ \\
\hline $\begin{array}{l}14 \\
28\end{array}$ & $\begin{array}{l}4.99 \\
7.02(3.6 \mathrm{I})\end{array}$ & $\begin{array}{l}4 \cdot 46 \\
6.93(4.25)\end{array}$ & $\begin{array}{l}4.73 \\
6.98(3.94)\end{array}$ & $\begin{array}{l}5.19 \\
6.60(4.66)\end{array}$ & $\begin{array}{l}5.71 \\
6.90(2 \cdot 71)\end{array}$ & $\begin{array}{l}5.45 \\
6 \cdot 75(3 \cdot 63)\end{array}$ \\
\hline & 5 & 6 & & 7 & 8 & \\
\hline 3 & $3 \cdot 84$ & $3 \cdot 46$ & 3.65 & $1 \cdot 75$ & 2.50 & $2 \cdot 13$ \\
\hline 17 & 4.19 & $4 \cdot 53$ & 4.72 & $4 \cdot 85$ & 5 II & 4.98 \\
\hline $3 \mathrm{I}$ & $6 \cdot 82(2 \cdot 98)$ & $6.95(3.49)$ & $6.89(3.24)$ & $7.20(5.45)$ & $7.54(5.04)$ & $7 \cdot 37(5 \cdot 24)$ \\
\hline & 9 & Io & & II & 12 & \\
\hline 7 & $4 \cdot 68$ & $4 \cdot 23$ & $4 \cdot 46$ & $4 \cdot 59$ & $5 \cdot 36$ & $4 \cdot 98$ \\
\hline 21 & 5.86 & 5.95 & 5.92 & 6.01 & $6 \cdot 13$ & 6.07 \\
\hline 35 & $8.19(3.51)$ & $7 \cdot 98(3 \cdot 75)$ & $8 \cdot 09(3 \cdot 63)$ & $8 \cdot 84(4 \cdot 25)$ & $8.86(3.50)$ & $8 \cdot 85(3 \cdot 87)$ \\
\hline & $\mathbf{1 3}$ & $\mathbf{I 4}$ & & 15 & 16 & \\
\hline ro & $4 \cdot 97$ & $3 \cdot 83$ & $4 \cdot 40$ & 4.64 & 3.96 & $4 \cdot 30$ \\
\hline 24 & 6.53 & $5 \cdot 62$ & 6.08 & $6 \cdot 84$ & $6 \cdot 20$ & $6 \cdot 52$ \\
\hline 38 & $6.42(1.45)$ & $7 \cdot 01(3 \cdot 18)$ & $6 \cdot 72(2 \cdot 32)$ & $8.94(4.30)$ & $8.01(4.05)$ & $8 \cdot 48(4 \cdot 18)$ \\
\hline Means & $5.64(2.89)$ & $5.22(3.67)$ & $5 \cdot 43(3 \cdot 28)$ & $5.62(4 \cdot 67)$ & $5.88(3.83)$ & $5.75(4.25)$ \\
\hline
\end{tabular}

Figures in parentheses are for the increases in erythrocyte counts during 4 weeks. Figures for any individual animal (indicated by a bold numeral) are in one block. 
There would appear to be no effect of sex on erythrocyte counts of these young rats, and in the rest of this paper no account is taken of differences in sex among weanling rats. Clear-cut are certainly the higher terminal values for the animals receiving the enriched diet, whether at $3^{\mathrm{I}}, 35$ or $3^{8}$ days after the experiment was begun. No difference is discernible between the animals at 28 days; this may be either because the time was too short or because the initial very low figure for animal no. 3 produced

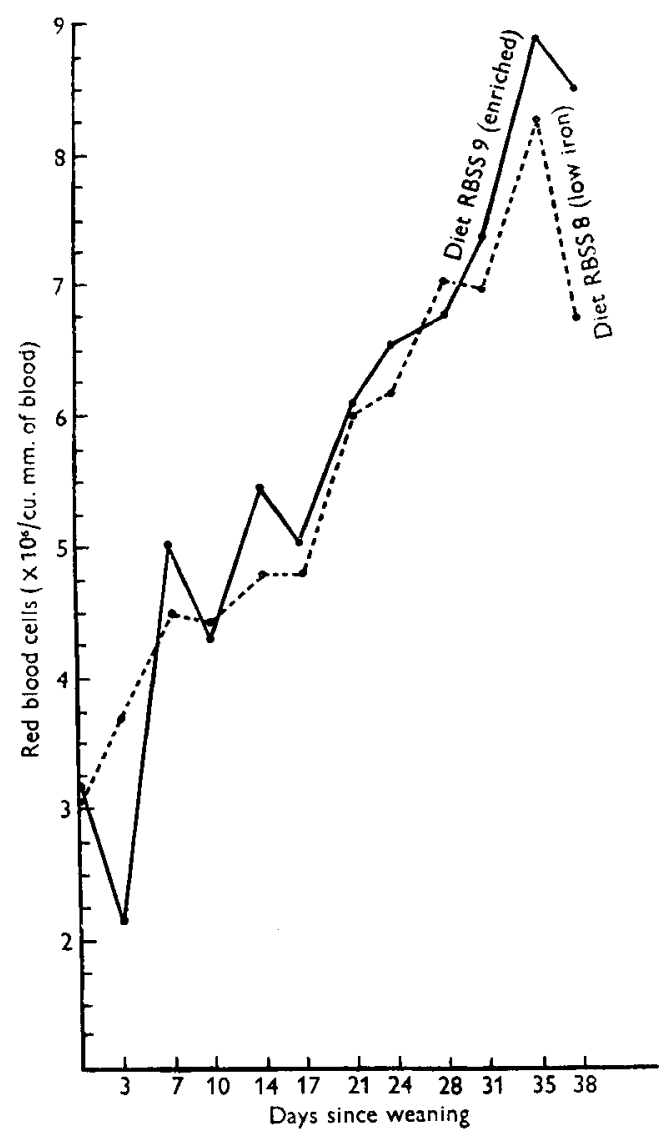

Fig. I. Mean erythrocyte counts of pairs of weanling albino rats.

a marked bias against the enriched diet, or because of both causes acting together. Statistical examination of these figures, for which we are indebted to Mr B. Basil, led to the conclusion that the enriched diet, RBSS 9, gave significantly greater accelerations of the rate of increase in R.B.C. in these newly weaned albino rats than did the original diet, RBSS 8 . This is further indicated in Fig. $I$; it must be emphasized that each point there plotted represents the mean of only two animals (though every fourth point on each curve represents the same two animals), and that there were very marked differences in the initial values of the animals used $\left(1 \cdot 94-4.19 \times 10^{6} \mathrm{cu} . \mathrm{mm}\right.$. for four animals at day $0,1 \cdot 75^{-3} \cdot 84 \times 10^{6} \mathrm{cu} . \mathrm{mm}$. for four animals at day 3 ).

As a further indication that diet RBSS 9 is practically as well as theoretically superior 
to diet RBSS 8 in haemopoietic potency, mating tests were carried out with the females used in the experiment just described. Certain of these animals, maintained on the same diet as during the experimental period, were mated $c .90$ days after the beginning of that period (they were thus between I I 5 and I 25 days old and weighed from II 0 to $15 \circ \mathrm{g}$ ). . Breeding performance was poor, but we were able to examine animals from two litters weaned on RBSS 8 and from one litter weaned on RBSS 9, as well as their mothers before parturition and at weaning. The results are summarized in Table 4 .

Table 4. Erythrocyte counts in albino rats on two diets

\begin{tabular}{|c|c|c|c|}
\hline \multirow[b]{3}{*}{ Type of animal } & \multicolumn{3}{|c|}{ Red blood cells ( $\times 10^{6} / \mathrm{cu} . \mathrm{mm}$. blood $)$} \\
\hline & \multicolumn{2}{|c|}{ Diet RBSS 8 (Jan.-Feb.) } & \multirow{2}{*}{$\begin{array}{c}\text { Diet RBSS 9 } \\
\text { (April-May) } \\
\text { Litter } 3\end{array}$} \\
\hline & Litter I & Litter 2 & \\
\hline Mother during pregnancy & 5.99 & $7 \cdot 07$ & $8 \cdot 16$ \\
\hline Mother at weaning & $7 \cdot 92$ & $10 \cdot 15$ & $8 \cdot 43$ \\
\hline \multirow[t]{2}{*}{ Young at weaning } & I.90-2.79 & $1 \cdot 31-2 \cdot 25$ & $3 \cdot 65-5 \cdot 21$ \\
\hline & (six animals) & (four animals) & (six animals) \\
\hline
\end{tabular}

The figures bear out the physical appearance of the different animals. Those from litter no. 3 were healthy and normal looking in every way; those from litters nos. I and 2 had the same pale appearance as the litters that first called our attention to the phenomenon under discussion.

The steady change in R.B.C. counts of weanling rats following the substitution of diet RBSS 9 for RBSS 8 is shown in Fig. 2. The numbers in parentheses show the number of weanlings, of either sex and chosen at random for examination on the day indicated. All these animals were examined on the 21st-23rd day after birth. The effect of the change in diet (on ${ }_{7} 7$ September) became almost immediately evident; the curve illustrates why no further signs of anaemia were observed in the colony atter the enriched diet had been used for only 2 or 3 weeks.

\section{A new type of strain difference}

We now turn to what we believe to be the most curious finding connected with this work. Nothing so far recorded need be regarded as more than an ex post facto justification of well-accepted views about the aetiology of nutritional (iron deficiency) anaemia in laboratory strains of Rattus norvegicus. Yet these views are apparently incomplete. We have for over 2 years been raising a colony of piebald (hooded) Norwegian rats, now approaching in number to those of our 'Wistar' stock. Brothersister mating of this second strain (PVG) has not proceeded for as long as in the albinos (WAG), though Dr E. C. Wood, from whom we got the foundation breeders in 1946, had carried this on for thirteen generations already, having obtained his own original breeders from the Lister Institute. The ancestors of that stock had come in their turn from Dr G. A. Hartwell's colony at King's College for Household and Social Science, London.

When surveying the position in September $1947^{-t}$ that is before we had replaced diet RBSS 8 by the enriched diet RBSS 9-we thought finally to confirm the existence 
of mild nutritional anaemia in the whole stock of both strains, and therefore picked at random a few animals from each, both adults and weanlings. The results of R.B.C. determinations are shown in Table $5(a)$.

The figures in Table $5(a)$, though few, are unequivocal. Adult males of both strains seem to show normal R.B.C. counts (though further work on this norm would seem

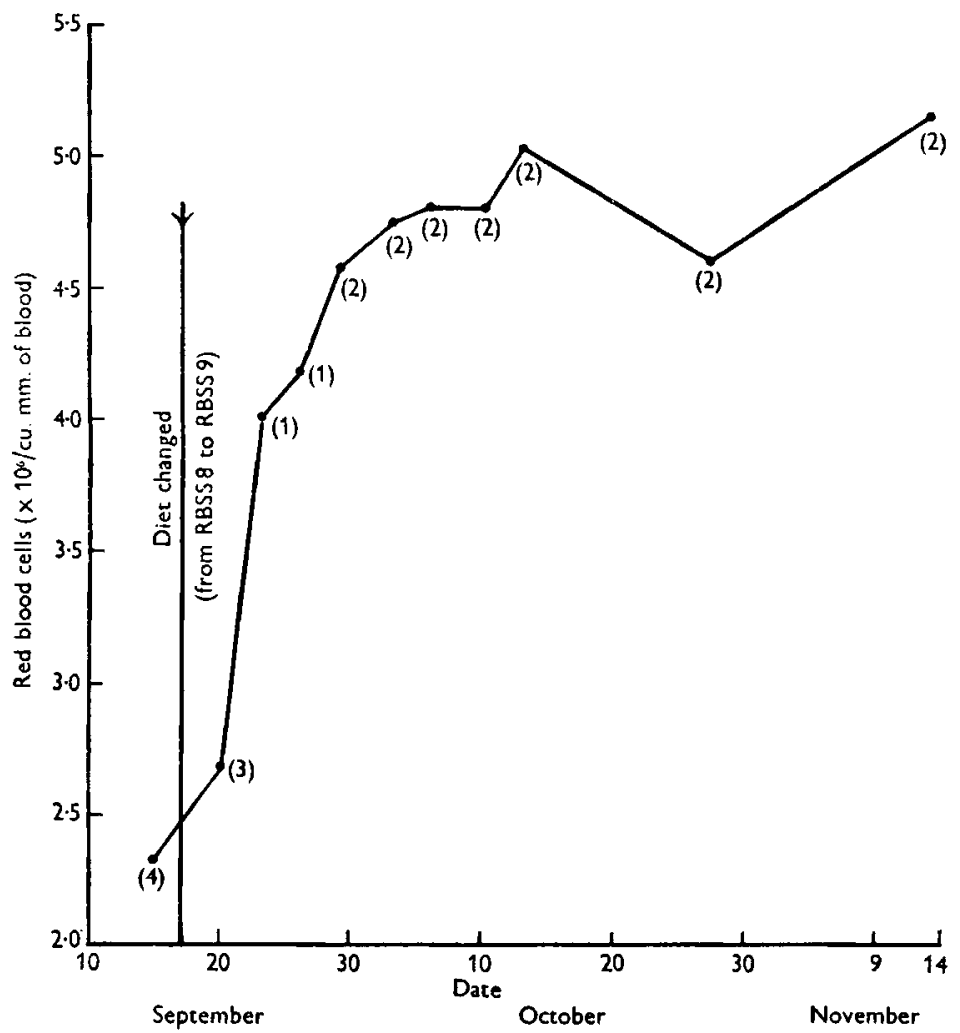

Fig. 2. Mean erythrocyte counts of weanling albino rats following change in iron content of stock diet. Figures indicate the number of animals.

desirable; the published figures are either out of date for modern laboratory strains (Donaldson, 1924) or inadequate (Griffith \& Farris, 1942)). Adult non-pregnant albino (WAG) females also appear normal, but there is a distinct lowering of the average R.B.C. count in the mothers, and pronounced nutritional anaemia in the litters. Yet the piebald (PVG) females and young suffered no such disability. No clinical signs of anaemia have ever been found in young or adults of this strain. For purposes of comparison Table $5(b)$ gives some current figures (at September 1948 , that is about 12 months after those recorded in Table $5(a)$ ), taken after the whole stock of both strains had been on diet RBSS 9 for about I year. There is clearly no difference between the R.B.C. figures for the two strains, and neither breeding does nor weanlings show any haematological evidence of anaemia. Clinical signs are also entirely absent. The very high figures shown by the piebald weanlings in 1947 on the old diet were 
again encountered in several piebald weanlings taken in mid-September 1947 at random from stock raised on RBSS 8. Erythrocyte values for six animals ranged from 5.5 to $6.25 \times 10^{6} / \mathrm{cu} . \mathrm{mm}$., with a mean value of 6.05 . After the change of stock diet further random piebald weanlings were examined; figures for six animals from mid-October

Table 5. Erythrocyte counts in rats of two strains

\begin{tabular}{|c|c|c|c|c|}
\hline \multirow[b]{3}{*}{ Type of animal } & \multicolumn{4}{|c|}{ Red blood cells ( $\times 10^{6} / \mathrm{cu} . \mathrm{mm}$. blood) } \\
\hline & \multicolumn{2}{|c|}{ Strain (WAG) } & \multicolumn{2}{|c|}{ Strain (PVG) } \\
\hline & $\hat{\sigma}$ & 9 & $\hat{\sigma}$ & q \\
\hline \multicolumn{5}{|c|}{ (a) On diet RBSS 8 in September 1947} \\
\hline Young adults & $\begin{array}{l}9 \cdot 04(158) \\
7.84(192)\end{array}$ & $\begin{array}{ll}8 \cdot 14 & (126) \\
8 \cdot 87 & (148)\end{array}$ & $\begin{array}{l}8 \cdot 21 \quad(224) \\
7 \cdot 72(240)\end{array}$ & $\begin{array}{l}8 \cdot 10(154) \\
7 \cdot 29(158)\end{array}$ \\
\hline Breeding stock & $\begin{array}{l}8 \cdot \text { r9 }(298) \\
8 \cdot 30(339)\end{array}$ & $\begin{array}{ll}7 \cdot 76 & (202) \\
6 \cdot 73^{*} & (278)\end{array}$ & $\begin{array}{l}7 \cdot 76(292) \\
7 \cdot 97(307)\end{array}$ & $\begin{array}{r}10.09(172) \\
8.98(182)\end{array}$ \\
\hline Weanlings & $\begin{array}{l}2.04(30) \\
1.70(31) \\
2.59 \dagger\end{array}$ & $\begin{array}{ll}2 \cdot 50 & (32) \\
2 \cdot 21 & (33) \\
2 \cdot 23 \dagger & \end{array}$ & $\begin{array}{l}6.24(37) \\
6.06(43)\end{array}$ & $\begin{array}{l}6 \cdot 54(43) \\
6 \cdot \mathrm{II}(48)\end{array}$ \\
\hline \multicolumn{5}{|c|}{ (b) On diet RBSS9 about I 2 months later } \\
\hline Young adults & $\begin{array}{l}8 \cdot 58(200) \\
8 \cdot 33(280)\end{array}$ & $\begin{array}{ll}8.54 & (130) \\
8.10 & (145)\end{array}$ & $\begin{array}{l}8.49(130) \\
9.07(220)\end{array}$ & $\begin{array}{l}8 \cdot 87(160) \\
8 \cdot 39(120)\end{array}$ \\
\hline Breeding stock & $\begin{array}{l}8 \cdot 63(240) \\
8.66(330)\end{array}$ & $\begin{array}{ll}8 \cdot 46 & (165) \\
8 \cdot 24 & (200)\end{array}$ & $\begin{array}{l}8.49(x 50) \\
9.07(220)\end{array}$ & $\begin{array}{l}8 \cdot 52(180) \\
8 \cdot 89(230)\end{array}$ \\
\hline Weanlings & $\begin{array}{l}4 \cdot 64(33) \\
4 \cdot 13(39)\end{array}$ & $\begin{array}{ll}4 \cdot 17 & (33) \\
4 \cdot 42 & (39)\end{array}$ & $\begin{array}{l}4 \cdot 48(36) \\
4 \cdot 41(36)\end{array}$ & $\begin{array}{l}4.71(34) \\
4.18(35)\end{array}$ \\
\hline
\end{tabular}

The weights of the animals $(\mathrm{g}$.) are given in parentheses.

to mid-November ranged from $4^{\cdot} 6$ to $5.9 \times 10^{6} / \mathrm{cu}$.mm., with a mean of $5 \cdot$. These are still a little higher than those found for the albino weanlings. However, by September 1948 , as appears in Table $5(b)$, the difference seems to have vanished.

It is perhaps worth recording the figures found in September ${ }_{1947}$, for four $F_{1}$ weanlings from crosses between albino and piebald parents, with those found at the same time for random pure-line weanlings (these have already been included in the figures given above):

\begin{tabular}{lcc}
\multicolumn{1}{c}{ Strain } & $\begin{array}{c}\text { No. of } \\
\text { animals }\end{array}$ & $\begin{array}{c}\text { Mean R.B.c. } \text { cu.mm. } \\
\left(\times 10^{6}\right)\end{array}$ \\
Albino (WAG) & 3 & $2 \cdot 67$ \\
Piebald (PVG) & 6 & $5 \cdot 10$ \\
$F_{1}$ hybrids & 4 & 4.20
\end{tabular}

DISCUSSION

It is not surprising that pregnant animals should be more sensitive to reduced consumption of an essential nutrient, especially if this is being supplied in the diet at a relatively low level, than should the non-pregnant, whether young or adult. It would appear that in our pregnant albino (WAG) does receiving diet RBSS 8-temporarily, moreover, deprived of supplementary iron in fresh liver-the intake of this element was marginal, so that the added strain of pregnancy and parturition tipped the balance toward some degree of anaemia. What was, on the other hand, less obviously to have 
been anticipated is the time relationship between iron intake and infantile hypochromic anaemia in rats. It will be recalled that the 'A-free' weanlings and the stock weanlings in which anaemia was first noticed had identical nutritional backgrounds up to their Ioth days from birth, all having been nourished in utero or $a b$ mammis by mothers receiving the 'low iron' stock diet RBSS 8 . When some of these weanlings were transferred at this stage to a diet adequate in iron (though devoid of vitamin $\mathrm{A}$ ), they maintained their R.B.C. counts at a level apparently normal for newly weaned animals. Presumably these animals, and their mothers, were also partaking marginally of iron until they enjoyed the effects of the richer vitamin A-free basal diet. There seems little doubt that the benefits accruing, therefore, are associated-as is the supply of vitamin A to weanlings on stock diet-less with transmission of the essential nutrient through the mother's placenta or mammary gland than with the stock diet directly consumed by the now active and partly independent youngsters. If anything may legitimately be argued from this work to human nutrition, it is perhaps fair to call attention to the importance of supplying adequate quantities of iron directly to infants during the weaning stages, whether they have previously been fed on the breast or artificially.

The difference in behaviour between weanlings (and their mothers) of our two rat strains was entirely unexpected. Though the scientific literature of the last decade contains references to many, mostly incidental, interstrain (intraspecific) differences in biological response, few refer especially to nutritive requirements, still fewer to inbred lines of rats, and none, as far as we are aware, to mineral needs. Our two strains of rats-contrary to what is currently believed about the albino and the 'hooded' varieties - are almost identical in weight, at any rate for the first few months of their lives, so that differences in iron requirements, or at least differences in susceptibility to the incidence of nutritional hypochromic anaemia, may well be the expression of a true interstrain difference in iron metabolism. This could have a practical bearing on the selection of suitable rat strains for any kind of haematological investigations. In general, this fortuitous finding of an apparently genetic influence on nutrient requirements may serve again to emphasize the need for much more information about the biological properties of 'pure line' animals, to the end that the most sensitive (and hence the most economical) strains may be used for those investigations, including nutritional studies, that purport to furnish some measure of quantitative information.

It is perhaps also permissible to point out that a stock diet, though it may from its achievements over a number of years be considered optimal, may be near to marginal in one or other essential nutrient; intentional changes in any constituent should be made with caution and enforced changes regarded with suspicion.

\section{SUMMARY}

1. Nutritional anaemia occurred, markedly in weanlings and less obviously in pregnant does, in an albino rat colony receiving a stock diet previously found satisfactory, when the diet was modified and the iron content unintentionally reduced through the replacement of National ( $85 \%$ extraction) flour by Canadian ' $D$ ' $(70-72 \%$ extraction) flour. 
2. Following addition of ferrous sulphate to the diet, and a simultaneous increase in its calcium content, already high, there was no recurrence of the outbreak.

3. Adult males or non-pregnant females showed few, if any, signs of reduction in red blood-cell count when they received the same diet as the slightly anaemic pregnant does and the markedly anaemic weanlings.

4. No animals, infant or adult, in a colony of piebald rats, kept alongside, under the same conditions and on the same diet as the albinos, showed any adverse effects of identical reduced iron intake and alteration of diet.

\title{
REFERENCES
}

Bacharach, A. L. (1933), Biochem. F. 27, 5 .

Donaldson, H. H. (1924). The Rat. Philadelphia: Wistar Institute.

Griffith, J. Q. J. \& Farris, E. J. (1942). The Rat in Laboratory Investigation. Philadelphia: J. B. Lippincott.

Loureiro, J. A. de (1931). Arch. Patol., Lisboa, 3, 72.

Nelson, E. M. (1928). Science, 68, 212.

\section{Nutrition of Domestic Rabbits}

\section{Variations in Carcass Composition of Rabbits Reared for Meat}

\author{
By J. C. D. HUTCHINSON and C. J. L. BAKER \\ Small Animal Breeding Station and Department of Poultry Nutrition, Animal \\ Nutrition Institute, School of Agriculture, Cambridge
}

(Received 15 November 1948)

It was shown by Hutchinson ( $1947 a$ ) that the fat content of rabbit carcasses cannot be predicted from their live weights or rates of increase in live weight because the fat content of the body or of the live-weight increase may be considerably influenced by the ration fed. This means that in experiments on rabbit-meat production the energy value of the meat for human consumption cannot be assessed even approximately from the increase in live weight. Since the chemical analysis of carcasses is laborious and expensive, an attempt has been made in this paper to find a method by which the fat content of the carcass may be predicted from anatomical data, in the hope that such a method would prove useful for field stations.

\section{METHODS}

To be of practical value a relationship between anatomical data and the fat content of the carcass should, so far as possible, be unaffected by environment, breeding and age. Therefore, in the attempt to work out a method of prediction, the material used was as heterogeneous as possible. The data available were the analyses of fifty-seven rabbit carcasses which were obtained from feeding experiments with substitute rations carried out during the war of $1939-45$. 